\title{
Rammya Mathew: Infant feeding, informed choice, and shared decisions
}

\author{
Rammya Mathew GP \\ London
}

Earlier this year Channel 4's Dispatches shone a light on misleading marketing practices used by multinational companies to promote infant formula. ${ }^{1}$ That same week The $B M J$ went public with its decision to stop accepting advertising for infant formula. ${ }^{2}$ Its announcement received a mixed reception on social media and reignited discussions among the public and medical professionals around infant feeding.

Both as a GP and as a mother, I want to see more being done to promote shared decision making around infant feeding. There's a strong public health imperative to improve breastfeeding rates, but as health professionals we also have a responsibility to empower women to make the choice that is right for them.

Prospective mothers mostly commit to breastfeeding, expecting it to be a "mother nature" experience, but they're equipped with little or no practical knowledge of what it involves. For some it will be a straightforward and fulfilling experience, but the reality is that many women struggle with it, particularly in the early days. Failing to give a woman a realistic picture of what to expect can set her up for potential misery, and it may stop her achieving her breastfeeding goals.

To support informed choice, health professionals charged with caring for women in the perinatal period should be able to impart accurate and unbiased information about breastfeeding, particularly the purported health benefits. I've been surprised by how difficult it is to find information such as absolute risk reductions and the numbers needed to feed, in relation to even the most established benefits of breastfeeding. Where are the
Cates plots and the decision aids to support shared decision making?

As an advocate of shared decision making, I find the frequently touted slogan "breast is best" uncomfortable. Instead, I see it as my role to help a woman decide what's best for her and her baby in her unique set of circumstances. The choice of whether to breastfeed or not is usually determined by a multitude of factors including a woman's interpretation of the benefits of breastfeeding, the value she places on it as an essential act of motherhood, and whether it works for her and her family as part of the complex picture of work and family life.

Infant feeding is an issue that needs to be looked at holistically, and we have to acknowledge that breastfeeding, although undoubtedly advantageous at a population health level, will not be deemed the best option by every mother. As we say goodbye to the glossy ads, I hope that we now have an opportunity to bring evidence to the fore and to refocus the debate around infant feeding, so that it becomes firmly centred around informed choice and shared decision making.

Competing interests: I have read and understood BMJ policy on declaration of interests and declare that I have no competing interests.

Provenance and peer review: Commissioned; not externally peer reviewed.

Dispatches: the great formula milk scandal. Channel 42019 Mar. https://www.channel4. com/programmes/dispatches/on-demand/69095-001. (Login needed.)

2 Godlee F, Cook S, Coombes R, El-Omar E, Brown N. Calling time on formula milk adverts. BMJ 2019;364:11200. 10.1136/bmj.l1200 30880279

Published by the BMJ Publishing Group Limited. For permission to use (where not already granted under a licence) please go to http://group.bmj.com/group/rights-licensing/ permissions 